\title{
Uma outra lógica: análise da obra $O$ outro pé da Sereia, de Mia Couto, sob a perspectiva de estratégias textuais que se alicerçam sobre olhares múltiplos
}

\author{
Lílian Paula Serra e Deus ${ }^{1}$
}

RESUMO: Nesse artigo busca-se fazer uma análise da obra $O$ outro pé da sereia, de Mia Couto, partindo-se da premissa de que a obra foi estrategicamente construída para suscitar olhares outros que fogem aos preestabelecidos pelo ocidente. São muitas as histórias que se entrecruzam, embora os pontos de vista sobre elas não sejam os mesmos, o que corrobora a ideia de que a obra, a todo o momento, questiona o conceito de uma única perspectiva, uma única verdade. Uma mesma história pode possuir muitas verdades e o autor vale-se de estratégias textuais significativas para suscitar esses questionamentos. O objetivo deste artigo é investigar como essas estratégias de construção textual corroboram essa linha de pensamento outra que, de certa forma, desconstrói toda uma lógica de pensamento ocidental.

ABSTRACT: In this paper the novel $O$ outro pé da sereia, by Mia Couto, will be analyzed from the premise that the work was strategically constructed to raise some impressions aside from the Western ones. There are many stories that intertwine, although the points of view on them are not the same which supports the idea that the work questions the concept of a single perspective, a single truth. The same story can have many truths and the author draws on substantial textual strategies to raise those questions. The aim of this paper is to investigate how these strategies of textual construction corroborate this thought that, in a way, deconstructs an entire logic of Western thought.

PALAVRAS-CHAVE: O outro pé da sereia. Estratégias de construção textual. Múltiplas perspectivas.

KEYWORDS: O outro pé da sereia; textual construction strategies; multiple perspectives.

Doutoranda em Literaturas de Lingua Portuguesa, PUC Minas.
lilianedeus@gmail.com




\section{INTRODUÇÃO}

Como enxergar o tempo? O que é a morte? Como ler a História; sobre o peso de que tradições? Quantas versões há para uma mesma "História"? De onde ela é contada? Como um mesmo fato pode suscitar olhares tão diferentes?

Esses são alguns dos questionamentos que a obra $O$ outro pé da sereia abarca.

Derrida, em sua proposta de Desconstrução ${ }^{2}$, já nos alerta para a necessidade de se enxergar além do logocentrismo, manifestação da metafísica ocidental, e ir à procura de significados para além da nossa lógica de pensamento binário. Ainda estamos muito "colados" na ideia de sim ou não, de inferior ou superior, de um ou outro, em vez de enxergar, quem sabe, "uma terceira margem do rio".

Essa importância da metafísica na tradição cultural do ocidente impõe verdades que, segundo o teórico franco-argelino, nada mais são que construções arbitrárias de preconceitos e de pressuposições.

Mignolo (2003), para além do que afirma Derrida acerca do desconstrucionismo, aponta que:

Desconstruir a história do interior da "historiografia" e do "logocentrismo ocidental" é sem dúvida uma tarefa necessária. Mas a descolonização da história é sem dúvida uma tarefa necessária e distinta, que não se pode reduzir ou associar à primeira. Na descolonização uma jogada transdisciplinar é acompanhada, diferentemente da desconstrução, de uma perspectiva a partir das margens exteriores do mundo colonial/moderno onde a diferença colonial foi definida e mantida. (MIGNOLO, 2003, p. 436).

A necessidade de uma outra lógica, que perpassa as relações de poder, presente nas reflexões de Mignolo (2003) é também percebida na tessitura de $O$ outro pé da sereia. Ao pensarmos, por exemplo, na maneira como os capítulos são dispostos entre tempos distintos e na construção das personagens, percebemos que há uma correlação entre esses tempos e essas personagens e que essas construções, por vezes, fogem a uma lógica ocidental.

Os capítulos são dispostos de forma a entrecruzar tempos cronológicos distintos: 1560 e 2002. Outros tempos que não os cronológicos também são encenados na obra, mas aterei meu olhar, principalmente, às datas marcadas ao longo da obra (1560 e 2002) e à forma com que elas se relacionam com a construção das personagens.

Segundo Hampatê Bâ:

\footnotetext{
${ }^{2}$ Termo proposto pelo filósofo francês Jacques Derrida, nos anos sessenta, para um método ou processo de análise crítico-filosófica que tem como objetivo imediato a crítica da metafísica ocidental e da sua tendência para o logocentrismo, incluindo a crítica de certos conceitos (o significado e o significante; o sensível e o inteligível; a origem do ser; a presença do centro; o logos, etc.) que tal tradição havia imposto como estáveis.
} 
(...) Nas narrativas africanas em que o passado é revivido como uma experiência atual, de forma quase intemporal, às vezes surge certo caos que incomoda os espíritos ocidentais. Mas, nós, nos encaixamos perfeitamente nele. Sentimo-nos à vontade como peixes num mar onde as moléculas de água se misturam para formar um todo vivo. (Hampaté Bâ, 1986).

Na obra de Mia Couto são muitos os momentos em que os tempos se imbricam: as personagens de um tempo cronologicamente marcado como 1560 parecem ser as mesmas presentes na narrativa marcada pela data de 2002. Pelo grande lapso temporal, como poderia uma personagem de um tempo tão passado ainda estar presente em 2002 ? Obviamente por trás dessa estratégia de construção textual há muitos questionamentos não só acerca da noção de tempo como nós ocidentais o marcamos, mas também no que concerne à questão identitária e à questão de como há outras maneiras de lidar (com) e de se enxergar a morte que não unicamente as estabelecidas pelo ocidente. A possibilidade, por exemplo, de um olhar outro que não somente o ocidental no que diz respeito ao conceito temporal pode ser percebido por meio do seguinte trecho: americano.

- Peço desculpas se lhe vamos tomar tempo, começou por dizer o

-Não tem problema. Para nós, africanos, o Tempo é todo nosso. $O$ branco tem o relógio, nós temos o tempo. (COUTO, 2006, p.148)

No que concerne à questão da morte dentro das culturas tradicionais africanas, Odete Semedo (2010) aponta para a noção de que mesmo após a morte, os constituintes de uma determinada linhagem (djorson) continuam a exercer seus papéis hierárquicos dentro delas, envolvem-se em lutas e guerras em benefício de sua linhagem. Continuam, portanto, exercendo seu poder e força dentro da linhagem e da comunidade.

São vários os momentos em $O$ outro pé da sereia que o conceito de morte é trazido numa concepção distinta da do ocidente, a começar pela própria epígrafe do livro:

Os que morreram não se retiraram.

Eles viajam na água que vai fluindo.

Eles são a água que dorme.

Os mortos

não morreram.

Eles escutam os vivos e as coisas

Eles escutam as vozes da água (Birago Diop) 
Desde que em alguma outra parte é que vivemos Palavra)

E aqui é só uma nossa experiência de sonho... (Guimarães Rosa, Ave

Em alguns momentos não se sabe ao certo se determinada personagem está viva ou "morta":

-Meu marido me confesse: você já morreu?

-Não, tudo isto vem da estrela, mulher.

-Mas, qual estrela?

-A que enterrei no nosso quintal. (COUTO, 2006, p.11)

A mulher anuiu, engolindo o canto. Permaneceu calada até que, ao fim da tarde, chegaram ao rio Mussenguezi. Contemplava o marido caminhando como uma queimada na extensão da savana. De repente se alvoroçou. Porque lhe pareceu que Zero não deixava pegada atrás de si.

-Zero?

-Diga?

—Nada, era só para escutar a sua voz. (COUTO, 2006, p.33)

- A avó Lela foi escrava. Morreu no chibalo.

-Afinal, havia uma escrava? Por que não disseram logo?

- São as boas maneiras, Dona Rosie. Nós só podemos falar da nossa gente quando ela já morreu.

- Mas essa avó já morreu.

—Sabemos La nós quando morremos... (COUTO, 2006, p. 326)

Segundo Bhabha:

É na emergência dos interstícios - a sobreposição e o deslocamento de domínios da diferença - que as experiências intersubjetivas e coletivas de nação [nationness], o interesse comunitário ou o valor comercial são negociados.( Bhabha, 1998, p. 21)

Ainda segundo o autor:

Os termos do embate cultural,seja através de antagonismo ou afiliação, são produzidos performaticamente. A representação da diferença não deve ser lida apressadamente como reflexo de traços culturais ou étnicos preestabelecidos, inscrito na lápide fixa da tradição. A articulação social da diferença, da perspectiva da minoria, é uma negociação complexa, em andamento, que procura conferir autoridade aos hibridismos culturais que emergem em momentos de transformação histórica. O "direito" de se expressar a partir da periferia do poder e do privilégio autorizados não depende da persistência da tradição; ele é alimentado pelo poder da tradição de se reinscrever através das condições de contingência e de contraditoriedade que presidem sobre a vida dos que estão "na minoria". O reconhecimento que a tradição outorga é uma forma parcial de identificação. Ao reencenar o passado, este introduz outras temporalidades culturais incomensuráveis na invenção da tradição. Esse processo afasta qualquer acesso imediato a uma identidade original ou a uma tradição "recebida". (Bahbha,1998, p. 20-21) 
A obra $O$ outro pé da sereia parece dialogar em muitos aspectos com a perspectiva de Bhabha. A história das navegações portuguesas, da colonização e do neocolonialismo é retomada e recontada sobre uma perspectiva que não é somente a do colonizador. Outros pontos de vista são propostos e para tal é imprescindível a forma como as personagens são construídas e a voz que a elas é dada. Para além disso, as identidades são a todo tempo negociadas e as personagens parecem estar todas situadas em um entre-lugar, o que corrobora com o questionamento de Bhabha:

De que modo se formam sujeitos nos "entre-lugares", nos excedentes da soma das "partes" da diferença (geralmente expressas como raça/classe/gênero/etc.) (Bhabha, 1998, p. 20)

A personagem D. Gonçalo da Silveira, jesuíta português que segue de Goa, na Índia, com o propósito de alcançar o reino de Monomotapa, na África, e converter o seu imperador à fé cristã, traz em seu discurso muito do discurso da história oficial, do discurso do colonizador, mas ao mesmo tempo permite que em sua embarcação sejam praticados alguns rituais tidos como pagãos:

A nau Nossa senhora da Ajuda acaba de sair do porto de Goa, rumo a Moçambique. Cinco semanas depois, em Fevereiro de 1560 chegará à costa africana (...) Nos barcos viajam marinheiro, funcionários do reino, deportados, escravos. Mais que todos, porém, a nau conduz D. Gonçalo da Silveira, o providencial dos jesuítas na Índia portuguesa. Homem santo, dizem. O jesuíta faz-se acompanhar pelo padre Manuel Antunes, um jovem sacerdote que estreava nas andanças marítimas.

O propósito da viagem é realizar a primeira incursão católica na corte do Império Monomotapa. Gonçalo da Silveira prometeu a Lisboa que baptizaria esse imperador negro (...) Por fim, África inteira emergiria das trevas e os africanos caminhariam iluminados pela luz cristã.

A estátua de Nossa Senhora, benzida pelo Papa, é o símbolo maior dessa peregrinação. Silveira jurou que a imagem da sagrada só repousaria em terras da Mãe Ouro, na corte do Monomotapa. Mas a santa quase ficava em Goa, aprisionada nas lamacentas margens do rio Mandovi (COUTO, 2006, p. 52).

-Autorize o batuque D. Gonçalo.

-Mas, D. Filipa, eu não posso...

-Pode sim. Eu mesma há muito que escuto batuque dos cafres. São ritmos tão belos, que Deus vai gostar de os escutar. (...) Não tardou que viesse a resposta: as danças estavam autorizadas. (COUTO, 2006, p. 206)

Já o padre Manuel Antunes relativiza e, por vezes, contrapõe esse discurso ao questionador os valores do colonizador:

(...) o que Manuel Antunes iria confessar era realmente penoso: ele acabara de deitar para o fogo o caderno de viagem. As anotações da travessia, o registro diário dos acontecimentos e descobertas, e mesmo os testamentos dos falecidos, tudo isso se consumia entre labaredas (... )

-E por que o fez? Por que queimou o caderno de bordo?

Antunes não ganhava clareza na resposta. Escrever para ele se tornara num fardo. O grão de areia, a gota do mar, o elefante compacto e a 
lágrima leve, tudo se convertia em sua posse desde que fixado em letra. Quando o lançou no fogo foi para se aliviar desse peso(...)

— Vou lhe confessar uma coisa: este barco está me conduzindo para longe da fé (...)

- Você, caro Manuel, põe na sua ideia a relevância da nossa missão no Monomotapa?

—É exatamente isso que me pergunto, D. Gonçalo: tem sentido tudo isso, D. Gonçalo?

- Que pergunta é essa?

— Tem sentido irmos evangelizar um império de que não conhecemos absolutamente nada?

- Você está cansado e o cansaço é inimigo do bem pensar.

-Pois eu nunca estive mais lúcido. Já pensou bem? Estamos descobrindo terras que nunca conheceremos, estamos mandando em gente que nunca governaremos.

- Cale-se peço-lhe que não blasfeme.

- Como iremos governar de modo cristão continentes inteiros se nem neste pequeno barco mandam as regras de Cristo? (COUTO, 2006,p.160)

Em $O$ outro pé da sereia perpassa a ideia de que nada é fixo, sobretudo conceitos construídos culturalmente. $\mathrm{O}$ conceito de morte deve ser encarado à luz de cada cultura. E quando essas culturas se entrecruzam, esses conceitos devem ser negociados. O mesmo é válido para a noção de tempo/espaço. A história oficial também é questionada, pois ela abarca apenas uma perspectiva. Todos esses conceitos são trazidos por meio da obra para perspectivas várias, o olhar nunca é unilateral. Em consonância com esse pressuposto, as personagens são construídas de forma que as identidades também não sejam fixas. O padre Manuel Antunes, jesuíta, branco, se vê transformado em negro, metaforicamente pela alusão à cor da pele, mas principalmente pela adesão de valores com os quais passa a se identificar mais do que com os que havia trazido:

(...) Acho que estou ficando negro, padre.

-Negro?

- Sim, um cafre.

-Agora, começo a achar que você devia falar com o médico.

-Falo sério, vossa Reverência, sinto que estou mudando de raça.

Até dia 4 de janeiro, data do embarque em Goa, ele era branco, filho e neto de portugueses. No dia 5 de Janeiro, começara a ficar negro. Depois de apagar um pequeno incêndio no seu camarote, contemplou as mãos obscurecendo. Mas agora era a pele inteira que lhe escurecia, os seus cabelos se encrespavam. Não lhe restava dúvida, ele se convertia num negro.

-Estou transitando de raça, D. Gonçalo. E o pior é que estou gostando mais dessa travessia do que de toda a restante viagem. (COUTO, 2006, p.164-165).

Por muitas vezes o leitor se pergunta, por exemplo, se o padre Manuel Antunes de 1560 não seria o Barbeiro Arcanjo Mistura de 2002. Arcanjo Mistura já traz no 
próprio nome a ideia de imbricação: é arcanjo, mas é também mistura. No que concerne à personalidade, aspectos da personalidade de Arcanjo Mistura se imbricam com características de Padre Manuel Antunes, levando o leitor a questionar se essas semelhanças não seriam propositais. Essa identidade misturada, que aparece também com outras personagens, como Mwadia que por vezes se confunde com a própria sereia e em outros momentos parece ecoar a voz de Dia Kumari. Mwadia não por acaso já traz dentro do próprio nome também o nome de Dia ( Mwa/dia). Esses aspectos vão ratificando ao longo da obra a ideia de que as identidades não são fixas e de que ninguém é uma coisa só o tempo todo. Por meio dessa estratégia, há também a relativização da noção de tempo/espaço e da própria noção da morte. Para além disso, há também implícita a ideia de que as muitas histórias (colonialismo, neocolonialismo, etc) vão se repetindo por meio de personagens que também se repetem.

Jesustino, por exemplo, é uma personagem que está sempre mudando de nome para que supostamente livrasse sua irmã e si mesmo da culpa por ter se envolvido em uma relação incestuosa:

\footnotetext{
—Mude de nome Jesustino!

- Como?

Se ele saltitasse de nome, ela se sentiria menos culpada. Mudando de nome ele se afastaria daquele que, em tempos, fora seu irmão. (COUTO, 2006, p. 228).
}

A personagem Mwadia, quando decide encenar para os afro-americanos rituais de incorporação, ela também traz no seu discurso essa questão das identidades. Mwadia chama o afro-americano Benjamin Southman de D. Gonçalo e o que parece ser uma simples confusão reverbera a questão do neocolonialismo focalizada na figura do afroamericano:

Segure o livro, D. Gonçalo, sussurrou a moça.

Casuarino vacilou. Constança estava certa: a representação estava indo longe de mais. Mwadia actuava de modo tão verossímel, que o atemorizava a ponto do suor gotejar pelo anafado pescoço.

- Receba o livro, insistiu Mwadia.

- Receba, lá, repetiram os outros, em coro.

- Mas ela está a falar com D. Gonçalo.

(...) cravando o indicador no americano, sentenciou:

- O senhor vai ser morto!

-Quem eu?

_Sim, virão matá-lo pela noite. (COUTO, 2006, p.235). 
Mwadia, também por meio das encenações, faz com que tempos diversos se entrecruzem, pois o enterro da estrela que havia sido feito por Zero Madzero é retomado por ela em uma de suas encenações:

-Não enterrem a estrela, não façam isso!

-Que raio é que ela está dizendo?, interrogou-se, incomodado, Casuarino.

- A estrela está caindo, está caindo dentro de nós.

-Uma estrela?

- Sim, uma estrela. Atravessa o tempo, está cruzando os séculos, agora está caindo. Todos os nossos mortos ganharam luz nessa estrela. E vocês deixaram esfriar esse pedaço do céu. Foram vocês...

-Mas nós fizemos o quê, valha-nos Deus?!, torturava-se Jesustino.

-Vocês enterraram a estrela. Aqui no chão de Vila Longe, essa estrela foi sepultada. E vocês morreram nesse enterro. (COUTO, 2006, p.235-236).

Mwadia, cujo nome, não despropositadamente, significa "canoa", é quem promove esses encontros entre tempos tão distintos. É ela quem leva a santa de Vila Longe para Antigamente como se atravessasse mundos, espaços e tempos e os entrecruzasse fazendo com eles se inter-relacionem. Portanto, o que aconteceu em 1560 ecoa em 2002. Somos, pois, frutos de um passado de uma história ou de muitas histórias, mas que sempre se relacionam.

É importante ressaltar que a estrela tem significados diferentes para cada uma das personagens que com ela tem contato: um avião americano em missão secreta, uma estrela, a responsável pela suposta "morte" de Madzero, etc. Aqui se tem a noção que perpassa a obra: olhares bastante distintos para um mesmo fato. E é por meio dessas personagens que esses muitos pontos de vista são trazidos à cena.

A questão da colonização e do neocolonialismo em África são colocados em pauta por meio de perspectivas bem diferentes. É interessante considerar-se dois aspectos: de onde se fala e quem fala? Diante dessas perspectivas, há a visão do colonizador sobre a colonização representada por meio da personagem D. Gonçalo, por exemplo.

Há também o questionamento da colonização e o mais interessante é que o autor o faz criando uma personagem que inicia a viagem na condição de colonizador, mas vai se transformando e questionando seus próprios valores quando estes são postos acima dos valores dos demais, como acontece com o Padre Manuel Antunes, quando este 
personagem relata estar ficando negro ou quando queima o caderno de viagem como forma de não se aceitar fazendo parte de situações e acontecimentos que disseminam valores com os quais não mais compactua.

A visão do colonizado sobre si mesmo também é trazida de maneira interessante, através de Nimi Nzundi, por exemplo, que não rompe com suas tradições, apesar de aos olhos de Dia Kumari parecer fazê-lo:

"Cara Dia Kumari:

Critica-me porque aceitei lavar-me dos meus pecados. Os portugueses chamam isso de baptismo. Eu chamo de outra maneira. Eu digo que estou entrando em casa de Kianda. A sereia, deusa das águas. É essa deusa que me escuta quando me ajoelho perante o altar da Virgem.

De todas as vezes que rezei não foi por devoção. Foi para me lembrar. Porque só rezando me chegavam as lembranças de quem fui. Acontecia-me o inverso do que lhe sucedeu a si, Dia Kumari. As minhas mãos se juntavam e pegavam fogo. Em lugar de dedos me ardiam dez pequenas labaredas. Era, então, que outras mãos, feitas de água, se aconchegavam nas minhas e aplacavam aquela fogueira. Essas mãos eram as da Santa (...) Era a voz da Santa que me percorria por dentro. A voz tomava posse de mim. E agora que lhe escrevi essa carta, vejo que essa letra não me pertence, é letra de mulher. Meus pulsos delgados se recolhem ao peso de um cansaço de séculos. Meus dedos não têm gesto, meus dedos são o próprio gesto. Eu sou a Santa.” (COUTO,2006,p.114).

Nimi Nzundi não reza para a santa do colonizador como pensa a indiana, mas para Kianda. E é interessante observar que em vez de rezar diante da imagem da santa como manda a tradição do colonizador, ele a incorpora, "eu sou a santa" como preceituam os rituais da sua tradição.

Benjamin Southman e sua esposa Rosie assumem, por vezes, a imagem do neocolonizador em África. Trazem consigo a ideia de uma África idealizada, mitificada e querem a todo custo encontrá-la. E, se é esta África exótica que os americanos buscam encontrar, é exatamente ela que os moradores de Vila Longe tratam de encenar:

$\mathrm{Na}$ véspera da consulta, Casuarino mandou Singério à frente para instruir o curandeiro sobre a necessidade de manter a aparência primitiva. A comitiva de Vila Longe levava o norte-americano a uma excursão pela África mais profunda. A palavra de ordem era: Tudo selvagem, nada de modernices. E as instruções do empresário desciam ao detalhe:

-O telemóvel, por exemplo, ele que o esconda. Rádio a pilhas a mesma coisa. Quero tudo arcaico, tudo bem rústico. (COUTO, 2006, p. 270) 
Para além disso, Southman e Rosie acreditam ter as respostas e todo o entendimento acerca dessa África que assumem como verdadeira. A África que tomam por verdadeira é apenas aquela que repercute a história oficial. Mas ao longo da obra, esses mitos vão sendo desfeitos e a história oficial é contrastada por meio, por exemplo, da personagem Zeca Matambira:

Incrédulo, Benjamin Southman deixou cair o caderno. Casuarino tentou corrigir, mas o americano não permitiu. Aproximou-se de Zeca Matambira e, com tom paternal, quase doce, lhe inquiriu:

-Diga-me, meu amigo, você está a falar dos portugueses?

-Portugueses? Naquele tempo, nós éramos todos portugueses...

-Está a falar dos brancos?

- Estou a falar de pretos. Desculpe, de negros.

- Mas fale desses negros, desses vangunis...

-Esses negros vieram do Sul e nos escravizaram, nos capturaram e venderam e mataram. Os portugueses, numa certa altura, até nos ajudaram a lutar contra eles. (COUTO, 2006, p. 149)

Em $O$ outro pé da sereia ressoam, pois, as vozes do colonizador, do colonizado, do neocolonizador, etc. Os processos culturais híbridos são encenados, as identidades se relativizam e constroem sujeitos do entre-lugar. Os discursos são múltiplos e permeiam espaços limiares. O próprio título da obra abarca a noção de possibilidades de perspectivas: $O$ outro pé da sereia circunscreve a ideia de uma possibilidade outra, um outro pé. A santa passa ser também Kianda, Nzuzu, Mama Wati. Na visão dos portugueses, Nossa Senhora sem um dos pés é uma Nossa Senhora desfigurada. Já na visão dos africanos, o fato de a sereia ter um dos pés é o que a desfigura. Portanto, a imagem é a própria representação da hibridação que perpassa a obra e a maneira como ela é percebida vai sempre depender do olhar que a ela é lançado. 


\section{Referências Bibliográficas:}

BHABHA, Homi K. "Locais da cultura". In: BHABHA, Homi K. O Local da cultura. Belo Horizonte: Editora UFMG, 1998.

CANCLINI, Néstor García. Culturas Híbridas: estrategias para entrar y salir de La modernidad. Buenos Aires. Editorial Sudamericana, 1995. Contradcciones latinoamericanas.

MIGNOLO, Walter. "Uma outra língua, um outro pensamento, uma outra lógica". In: Histórias Locais/projetos globais: colonialidade, saberes subalternos e pensamento liminar. Belo Horizonte: editora UFMG, 2003.

COUTO, Mia. O outro pé da sereia. São Paulo: Companhia das Letras, 2006. 